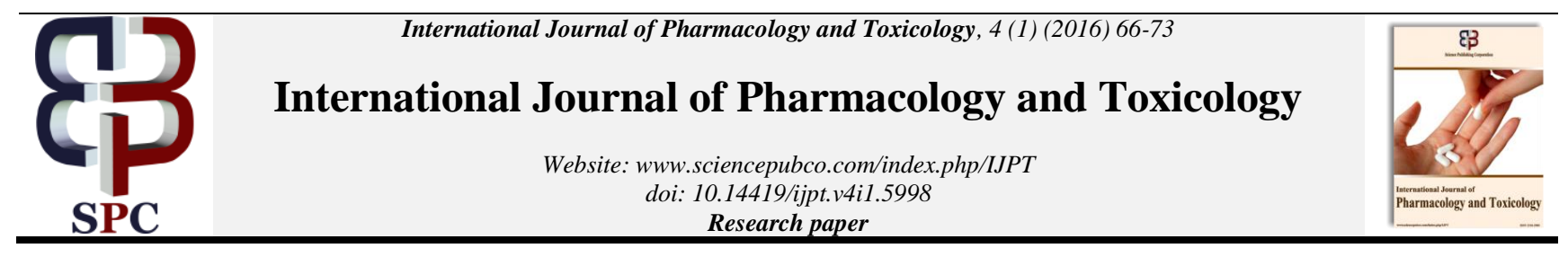

\title{
Pharmacokinetics of Lornoxicam in rabbits after single intravenous bolus and intramuscular administrations
}

\author{
Abubakr El-Mahmoudy * \\ Department of Pharmacology, Faculty of Veterinary Medicine, Benha University, 13736 Moshtohor, Egypt \\ *Corresponding author E-mail: a.elmahmoudy@fvtm.bu.edu.eg
}

\begin{abstract}
The pharmacokinetics of lornoxicam (a non-steroidal anti-inflammatory drug) at a dose of $0.4 \mathrm{mg} / \mathrm{Kg}$ body weight was evaluated after single intravenous (i.v.) and intramuscular (i.m.) bolus administrations in rabbits. An HPLC assay using pure lornoxicam base as a standard was used to measure its concentrations in plasma at prefixed time points up to 12 hours post administration. Following an i.v. bolus injection, the plasma concentration-time curves of lornoxicam were best represented by two-compartment open model. The drug was rapidly distributed and moderately eliminated with half-lives of distribution $\left(t_{1 / 2 \alpha}\right)$ and elimination $\left(t_{1 / 2 \beta}\right)$ of 0.238 and $2.611 \mathrm{~h}$, respectively. The volume of distribution was large with $\left(V_{d s s}\right)$ value of $1.499 \mathrm{~L}$. The total body clearance $\left(C l_{\mathrm{B}}\right)$ was $0.413 \mathrm{~L} / \mathrm{h}$. After i.m. bolus administration of the same dose, lornoxicam was moderately and completely absorbed in rabbits with an absorption half-life $\left(t_{1 / 2 a b}\right)$ of 1.228 $\mathrm{h}$ with peak plasma concentration $\left(C_{\max }\right)$ of $0.463 \mu \mathrm{g} / \mathrm{mL}$ attained at $1.512 \mathrm{~h}\left(T_{\max }\right)$ and systemic bioavailability of $99.79 \%$. The elimination half-life following i.m. administration was $2.283 \mathrm{~h}$. The extent of plasma protein binding percent was $98.9 \%$. The study recommends the use of lornoxicam in rabbits because of its good pharmacokinetic profile indicated by good absorption, bioavailability and plasma concentrations.
\end{abstract}

Keywords: Lornoxicam; Pharmacokinetics; Intravenous; Intramuscular; Rabbits.

\section{Introduction}

The importance of pain management and the use of non-steroidal anti-inflammatory drugs (NSAIDs) in animals has increased dramatically in recent decades. NSAIDs have the potential to relieve pain and inflammation without the myriad potential metabolic, hemodynamic, and immunosuppressive adverse effects associated with corticosteroids (Merck-Veterinary-Manual 2016). NSAIDs act by inhibiting cyclooxygenase (COX) enzyme subtypes $1 \& 2$ (Lirk et al. 2007). There are two types of COX-inhibitors, the traditional non-selective NSAIDs which block both types of COX. The second type is selective COX-2 inhibitors which have no or minimal affinity, and thus, no effect on COX-1. The development of the COX-2 selective inhibitors was intended to provide drugs that would offer the same pain-relieving and anti-inflammatory effects as the traditional NSAIDs without causing the gastric ulcers that have been associated with the pioneer drugs (Copeland et al. 1994).

Application of NSAIDs has been utilized on a large scale in human therapeutics. However, many of these agents have not been utilized yet similarly in veterinary practice in spite of their good potentials. COX-inhibitors are very important in symptomatic treatment of disease conditions and for specific treatment as well. In symptomatic treatment, they are prescribed in most cases together with the specific remedies to relieve variety of inflammatory symptoms such as fever, pain, swelling, congestion and edema. Moreover, they are the main or specific drugs used for treatment of chronic inflammatory conditions including rheumatism, rheumatoid, tendinitis, osteoarthritis, muscle aches, back aches, bursitis and menstrual cramps. In addition, they have special role post grafting to avoid graft rejection
Lornoxicam (Fig. 1) is a relatively new NSAID of the oxicam class. It is distinguished from the other established oxicams by a relatively shorter duration of action (Radhofer-Welte and Rabasseda 2000). Like all NSAIDs, it acts by inhibiting the metabolites of COX branch of arachidonic acid pathway. It inhibits both isoforms in the same concentration range i.e. COX-1/COX-2 $=1$. Thus, a perfectly balanced inhibition of COX-1 and COX-2 is achieved (Prasad Byrav et al. 2009).

A few pharmacokinetic studies on lornoxicam have been reported in man (Hitzenberger et al. 1989), (Zhang et al. 2005), (Liang et al. 2006) and monkey (El Dareer et al. 1990).

The aim of the present study was to evaluate the pharmacokinetic parameters of lornoxicam in New Zealand rabbits following its single intravenous (i.v.) bolus and single intramuscular (i.m.) administrations.<smiles>CN1C(C(=O)Nc2ccccn2)=C(O)c2sc(Cl)cc2S1(=O)=O</smiles>

Fig. 1: Structural Formula of Lornoxicam.

\section{Material \& methods}

\subsection{Study design}

The study was carried out as a longitudinal crossover design as described by (Grizzle 1965). The first phase of the study was de- 
signed for the single i.v. bolus administration; while the second phase was for the single i.m. administration. The washout period between the two phases was fifteen days. All animals received a single i.v. dose of lornoxicam in the first phase and, after the wash out interval, received the same dose via the i.m. route in the second phase. All measures were undertaken to minimize animal suffering as possible as it could be.

\subsection{The drug}

Lornoxicam is a tenoxicam derivative (Chlortenoxicam), with chemical name: 6-chlor-4-hydroxy-2-methyl-N-2-pyridyl-2Hthieno [2], [3-e]-1, 2-thiazine-3-carboxamide1,1-dioxide; molecular formula: $\mathrm{C}_{13}-\mathrm{H}_{10}-\mathrm{Cl}-\mathrm{N}_{3}-\mathrm{O}_{4}-\mathrm{S}_{2}$ and molecular weight: 371 . The drug was obtained as lyophilized powder for injection produced by Nycomed ${ }^{\circledR}$ GmbH (Linz, Austria) under trade name Xefo ${ }^{\circledR}$. It is formulated as $8 \mathrm{mg} / \mathrm{vial}$. The dose of the drug to human is 8 $\mathrm{mg} / \mathrm{day}$. The dose given to each rabbit was adjusted to $0.4 \mathrm{mg} / \mathrm{Kg}$ according to (Paget and Barnes 1964). The supplied drug powder was solubilized in sterile water for i.v. administration, where the concentration of the drug concentration is adjusted to $0.8 \mathrm{mg} / \mathrm{mL}$, and a rabbit weighing $2 \mathrm{Kg}$ received $1 \mathrm{~mL}$. The standard lornoxicam pure powder used in HPLC analysis was a kind gift from Sigma Pharmaceutical Company, Quesna, Egypt.

\subsection{Experimental animals}

Twelve healthy, New Zealand male rabbits, with average body weight of $2.5 \mathrm{Kg}$ were used. Animals were numbered and accommodated in a suitable pen under hygienic condition with controlled temperature $\left(22 \pm 1^{\circ} \mathrm{C}\right)$, humidity $(60 \pm 10 \%)$ and light $(12 \mathrm{~h}$ per day) for two weeks before being used to ensure their clearance from medications. Food and water were available ad libitum. Six rabbits were used for the two-phase crossover experiment, and the rest of animals were used for separation of clear plasma.

\subsection{Drug administration and blood sampling}

In the first phase of experiment (Group I), animals were numbered $1-6$, and received $0.4 \mathrm{mg} / \mathrm{Kg}$ dose as a single i.v. bolus into the ear vein. The second phase was performed after a 15 -day washout period (Group II), where the same animals were numbered as 6 12 , and received $0.4 \mathrm{mg} / \mathrm{Kg}$ dose as a single i.m. dose in the thigh region. According to (Pabst and Jaeger 1990), sampling continued for 3-5 biological half-lives in order to obtain correct pharmacokinetic parameters from plasma-concentration (C-T) curves. Five$\mathrm{mL}$ lithium heparinised vacutainer tubes and 22-G disposable needles were used for collection of $2 \mathrm{~mL}$ of blood at each bleeding point at the following intervals: $0.083,0.167,0.25,0.5,1,2,4,8$ and 12 (Phase-I); and at 0.25, 0.5, 1, 2, 4, 8 and 12 (Phase-II). The collected blood samples were immediately chilled and centrifuged at $10,000 \mathrm{x} g$ for $10 \mathrm{~min}$. The harvested plasma samples were then stored at $-50{ }^{\circ} \mathrm{C}$ until HPLC assay.

\subsection{Chemicals and reagents}

Methanol and water were HPLC-grade, from Wako Chemicals $\mathrm{GmbH}^{\circledR}$ (Neuss, Germany). Sodium Hydroxide, Sodium Dihydrogen Orthophosphate, Trichloroacetic acid were all AR (analytical reagent) grade chemicals, from BDH Chemicals Limited ${ }^{\circledR}$ (Poole, England). The drug-free plasma was sourced from animals kept on drug-free water and feed in the same experimental conditions.

\subsection{Lornoxicam HPLC assay}

\subsubsection{HPLC apparatus and chromatographic conditions}

The ChromGate ${ }^{\circledR}$ v 3.3 .2 chromatography manager software was used to control the HPLC system (Knauer ${ }^{\circledR}$, Berlin, Germany) which consisted of a pump (Smartline Pump 1000) with solvent delivery module (Smartline Manager 5000) equipped with an au- tosampler (Smartline Autosampler 3950), analytical column (Eurospher $100-5 \mathrm{C} 18 ; 250 \times 4.6 \mathrm{~mm}$ ) with a thermostat (Smartline Column Thermostat; from 5 to $85{ }^{\circ} \mathrm{C}$ ) and a variable wavelength ultraviolet detector (Smartline UV Detector 2600). The mobile phase was $0.1 \mathrm{M}$ Sodium dihydrogen o-phosphate ( $\mathrm{pH}-4.3$ ): Methanol in ratio of 45:55 (v/v), filtered through a $0.2 \mu \mathrm{m} \mathrm{mem-}$ brane filter, degassed, sonicated and used with flow rate of 1.0 $\mathrm{mL} / \mathrm{min}$. The UV detector was used to monitor the drug at wavelength of $375 \mathrm{~nm}$ with temperature maintained at $40{ }^{\circ} \mathrm{C}$. The retention time for lornoxicam under our experimental conditions was found and confirmed to be 12 min (it is, however, stated differently in the original method; but this may be attributed to the different environmental and experimental conditions, the different chromatography system used and the different material sources and species plasma as well). The sample run time was, therefore, set at 15 minutes.

\subsubsection{Assay procedure}

The Specimens of plasma were deproteinated by adding an equal volume of a precipitating solution (in case of unknown samples) or deproteinated and spiked with known concentrations of the study drug (in case of standard) as detailed below (Bhandari and Khisti 2012):

\subsubsection{Standard stock solutions and calibration}

A Standard stock solution of lornoxicam was prepared by dissolving $8 \mathrm{mg}$ drug in $0.3 \mathrm{ml}$ of $0.1 \mathrm{M} \mathrm{NaOH}$ and then diluting with mobile phase to final volume of $10 \mathrm{ml}$ in volumetric flask to get concentration $800 \mu \mathrm{g} / \mathrm{mL}$. This stock solution of lornoxicam was then serially diluted to $0.25,0.5,1,2,4$ and $8 \mu \mathrm{g} / \mathrm{mL}$ with the mobile phase. To construct the calibration plot, $0.5 \mathrm{~mL}$ of blank plasma, $0.5 \mathrm{~mL}$ of a lornoxicam calibration solution, $0.5 \mathrm{~mL}$ methanol and $0.5 \mathrm{~mL}$ of trichloroacetic acid $(10 \% \mathrm{w} / \mathrm{v})$ were added together in glass tubes. Each tube contents was vortex mixed for $3 \mathrm{~min}$ and centrifuged $(10,000 \times \mathrm{g}$ for $20 \mathrm{~min}$ at room temperature). After centrifugation, the supernatant of each concentration was harvested, filtered into auto-sampler vials using $0.45 \mu \mathrm{m}$ syringe filters. Auto-sample volume to be injected into HPLC system was adjusted at $50 \mu \mathrm{L}$.

\subsubsection{Preparation of plasma sample solutions}

To $0.5 \mathrm{~mL}$ of plasma taken at a bleeding point, $0.5 \mathrm{~mL}$ of the solvent used in lornoxicam calibration solutions $(0.3 \mathrm{ml}$ of $0.1 \mathrm{M}$ $\mathrm{NaOH}$ diluted with mobile phase to final volume of $10 \mathrm{ml}), 0.5$ $\mathrm{mL}$ methanol and $0.5 \mathrm{ml}$ of trichloroacetic acid $(10 \% \mathrm{w} / \mathrm{v})$ were added together in glass tubes. Each sample was vortex-mixed for 3 min and centrifuged $(10,000 \times g$ for $20 \mathrm{~min})$. After centrifugation the supernatant of each sample was harvested, filtered into autosampler vials using $0.45 \mu \mathrm{m}$ syringe filters. Auto-sample volume to be injected into HPLC system was adjusted at $50 \mu \mathrm{L}$.

\subsection{Plasma protein binding assay}

The extent of plasma protein binding was determined in vitro using ultrafiltration according to the method described by (Craig and Suh 1991). Drug-free plasma from healthy rabbits fortified with known concentrations of lornoxicam $(1,2$ and $4 \mu \mathrm{g} / \mathrm{mL})$ was used. One $\mathrm{ml}$ of each sample was placed on a conditioned semipermeable membrane (Centriflow Cones CF-50, Amicon Corp. ${ }^{\circledR}$, Lexington, MA, USA) resting on porous conical polyethylene support on the top of centrifuge tubes. The tubes were centrifuged at $1500 \mathrm{~g}$ for $60 \mathrm{~min}$. Plasma samples and their corresponding ultra-filtrates were assayed by the same HPLC method as described above. The percentage of plasma protein binding was calculated according to the following equation:

Protein binding $=\frac{\text { Total conc. }- \text { Ultrafiltrate conc. }}{\text { Total conc. }} \times 100$ 


\subsection{Pharmacokinetic analysis}

Pharmacokinetic parameters were derived from concentration vs time (C-T) curves obtained from the experimental concentrations of each individual animal, and reported as mean \pm SEM. Compartmental modelling of the drug C-T data was selected for analysis.

\subsubsection{Single intravenous bolus}

The plot of plasma C-T was fit to two-compartment open model that has been described by (Riegelman et al. 1968). This was on the basis of that the C-T curve was described by a bi-exponential equation and cannot be converted to a single straight line by converting plasma concentrations to the logarithmic domain as in occasion of one compartment open model. As simple linear regression cannot be used to estimate the parameters of the twocompartment model, the plasma C-T data were then linearized as two straight lines using a process called curve stripping (also known as the method of residuals or feathering) according to (Riggs 1964). The pharmacokinetic parameters were calculated according to equations integrated by (Baggot 1977), (Baggot 1978a), (Baggot 1978b) and (Rosenbaum 2012) with the aid of Microsoft Excel $^{\circledR}$ version 2013 software. The basic equation for the two-compartment model is:

$C_{p(t)}=A e^{-\alpha t}+B e^{-\beta t}$

Where, $C_{p(t)}$ is the concentration of drug in the plasma at a specified time $t ; \alpha$ and $\beta$ are both hybrid rate constants; A \& B are constant terms given by Y-intercepts.

The process of curve stripping can isolate the two-component exponential functions to allow "A and $\alpha$ " and " $\mathrm{B}$ and $\beta$ " to be determined from straight lines obtained from semi-logarithmic plots. Then, the micro rate constants $\left(\mathrm{K}_{12}, \mathrm{~K}_{21} \& \mathrm{~K}_{10}\right)$ and the rest of pharmacokinetic parameters were calculated from these four parameters.

Firstly, the macro-constant B was obtained by back-extrapolation of the terminal portion of C-T curve. The intercept of this line with the concentration axis was B. It has been calculated manually using a scientific calculator supporting regression analysis (Casio fx-9860GII, Casio Computer Co. Ltd, Tokyo, Japan was used in the present study) and by Excel ${ }^{\circledR}$ as well.

The macro-constant $\beta$ was obtained (as -slope) using any two points on the terminal (elimination) straight phase of the curve (or using a late point and B value for easy calculation) using the following equation:

$\beta=-\frac{\ln C_{\text {late }}-\ln B}{t_{\text {late }}-0}$

Secondly, the macro-constant A was obtained by the method of residuals, which means that the back-extrapolated $\beta$-phase values at early time points are subtracted from the experimental data during the initial phase (fast distribution). The intercept of the back-extrapolated line of residuals with the concentration axis was A. Also, it has been calculated manually using the calculator.

The macro-constant $\alpha$ was obtained as the (-slope) of the line of residuals plotted on the semi-logarithmic scale. It has been calculated using the following equation:

$\alpha=-\frac{\ln C_{\text {residual }}-\ln A}{t_{\text {early }}-0} \quad\left(h^{-1}\right)$

The intercept of the back-extrapolated overall C-T curve on the concentration axis was $\mathrm{C}^{\circ}$; it was the concentration of the drug at zero time. It was calculated as:

$C^{\circ}=A+B$

$(m g / L)$
The corresponding half-lives of the primary model parameters have been then obtained. A half-life was the time taken for the blood concentration of the drug to decline by $50 \%$ during the distribution $\left(t_{1 / 2 \alpha}\right)$ or elimination $\left(t_{1 / 2 \beta}\right)$ phase of the disposition curve; they have been calculated by the following expressions:

$t_{1 / 2 \alpha}=\frac{\ln 2}{\alpha}=\frac{0.693}{\alpha}$

$t_{1 / 2 \beta}=\frac{\ln 2}{\beta}=\frac{0.693}{\beta}$

The micro rate constants $\left(\mathrm{K}_{12}, \mathrm{~K}_{21} \& \mathrm{~K}_{10}\right)$ were then derived from the calculated values of $\mathrm{A}, \mathrm{B}, \alpha$ and $\beta$ as stated below.

$K_{12}$ : is the rate constant for inter-compartmental distribution from central to peripheral compartment. It was calculated from the equation:

$K_{12}=\frac{A B(\beta-\alpha)^{2}}{C^{\circ}(A \beta+B \alpha)} \quad\left(h^{-1}\right)$

$K_{2 l}$ : is the rate constant for inter-compartmental re-distribution from peripheral to central compartment. It was calculated from the equation:

$K_{21}=\frac{A \beta+B \alpha}{A+B} \quad\left(h^{-1}\right)$

$K_{10}$ : is the rate constant for elimination. It was calculated from the equation:

$K_{10}=\frac{C^{\circ}}{A / \alpha+B / \beta}$

Pharmacokinetic parameters describing distribution volumes and clearances are then calculated as stated below.

The volume of distribution $\left(V_{d}\right)$ of a drug is the ratio of the amount of drug in the body at any time to the plasma concentration at that time. In a two-compartment model, the volume of distribution changes after the administration of a dose, and at different times one of three volumes of distribution may hold: $V_{d(c)}, V_{d(\beta)}$, and $V_{d}$ (ss).

The volume of the central compartment $\left(V_{d(c)}\right)$ is the volume of distribution at time zero, immediately after i.v. administration of the drug. At that time the entire dose was contained within the central compartment which represents blood and vascular bed of highly perfused organs, it was obtained from the equation:

$V_{c}=\frac{D(m g)}{C^{\circ}(m g / L)}$

The term $\left(V_{d(\beta)}\right)$ is the volume of distribution at the end of distribution phase. At time zero the entire dose was contained within the central compartment and $V_{d}=V_{c}$. The drug then gradually distributes to the peripheral compartment (tissues; $V_{t}$ ). As the physical volume through which the drug distributes increases, the volume of distribution increases. However, the fall in the plasma concentration during this period is not only dominated by distribution, but some drug elimination occurs. Once the distribution phase has been completed, the plasma concentration and the amount of drug in the body fall in parallel, the volume of distribution was then constant and was called $V_{d(\beta)}$. However, its dependence on elimination may limit its use. It is also named $V_{d(\text { area })}$ as it is calculated in terms of area under $\mathrm{C}$ - $\mathrm{T}$ curve $(A U C)$ by the following equation:

$V_{d(\beta)}=\frac{D}{A U C * \beta}=\frac{D}{(A / \alpha+B / \beta) \beta}$

The term $\left(V_{d(s s)}\right)$ is the volume of distribution at the steady state at which the loss of drug from elimination was matched exactly by the gain of drug from administration. True equilibrium exists between the compartments, and $V_{d}=V_{c}+V_{t}$. It is a true primary pharmacokinetic parameter that reflects only distribution and was 
not influenced by elimination, so it is most robust. It has been calculated from the following equation:

$V_{d(s s)}=\frac{K_{12}+K_{21}}{K_{21}} * V_{c}$

Clearance of a drug has been expressed in terms of the volume of blood cleared of the drug by the various elimination processes (biotransformation and excretion) per unit time and body weight. Therefore, clearance is a measure of the ability of the organs of elimination to remove drug from the plasma, and it is a constant of proportionality between the rate of elimination at any time and the corresponding plasma concentration. The rate of elimination of a drug has been expressed using either the elimination rate constant $\left(\mathrm{K}_{10}\right)$ or clearance kinetic parameter that has been obtained by the following equation:

$C l_{(B)}=\frac{D}{A U C}$

The value can be divided by 60 to get the clearance rate per minute not per hour.

The distribution clearance $\left(C l_{d}\right)$ is a measure of the ability of a drug to pass into and out of the tissues of the peripheral compartment. It is determined by the permeability of the drug across the capillary membrane in these tissues as well as the blood flow to the tissues. It has been obtained from one of the following equations:

$K_{12}=\frac{C l_{d}}{V_{c}} \quad$ or $\quad K_{21}=\frac{C l_{d}}{V_{t}}$

$V_{t}$ : is apparent volume of tissue (peripheral) compartment which represents poorly perfused organs as muscle and adipose tissues, it was obtained from the following equation:

$V_{t}=V_{d(s s)}-V_{c}$

Both of the ratios $\left(K_{12} / K_{21}\right)$ and $\left(V_{t} / V_{c}\right)$ are measures of the relative distribution of the drug between the two compartments. A large ratio indicates that a large fraction of the drug in the body resides in the peripheral compartment.

\subsubsection{Single intramuscular dose}

In this occasion the drug was not administered directly to the systemic circulation. Therefore, access of the drug to the blood from its site of administration (absorption) is a critical pharmacokinetic parameter. The plasma concentration increases gradually as a result of absorption, a peak was achieved, and then after some time after drug administration, the entire dose was absorbed and the plasma concentration will decline in a mono-exponential manner, due only to first-order drug elimination. The process of absorption brings two additional parameters into the pharmacokinetic model: the bioavailability factor $(F)$ and a parameter for the rate of drug absorption, the first-order absorption rate constant $\left(K_{a b}\right)$. Unlike clearance and volume of distribution, these two parameters were properties not only of the drug itself but also of the dosage form, and can vary from one brand of a drug to another.

The plasma concentration at any time after the i.m. dose can be described by the following bi-exponential equation:

$C_{p(t)}=\frac{F * D * K_{a b}}{V_{d} *\left(K_{a b}-K_{e l}\right)} *\left(e^{-K_{e l} * t}-e^{-K_{a b} * t}\right)$

$(m g / L)$

This basic equation is bi-exponential and its curve has not been made linear by transforming the data to the logarithmic scale. Therefore, the parameters have been obtained by linearizing the data through curve stripping as stated below. The first-order elimination rate constant $\left(K_{e l}\right)$, elimination half-life $\left(t_{1 / 2(e l)}\right)$, first-order absorption rate constant $\left(K_{a b}\right)$, absorption half-life $\left(t_{1 / 2(a b)}\right)$ and $\mathrm{Y}$ intercept were initially determined and the rest of parameters were then derived.
$K_{e l}$ gives a measure for the rate of drug elimination after complete absorption of the entire dose; it equals the (-slope) of the terminal phase of the curve and has been calculated from the following equation:

$K_{e l}=-\frac{\ln C_{\text {late }}-\ln I_{B}}{t_{\text {late }}-0}$

$t_{1 / 2(e l)}$ gives a measure to determine the approximate time for elimination to be completed (after 3-5 half-lives for example); it was calculated in terms of $\mathrm{K}_{\mathrm{el}}$ from the following equation:

$t_{1 / 2(e l)}=\frac{\ln 2}{K_{e l}}=\frac{0.693}{K_{e l}}$

$K_{a b}$ gives a measure for the rate of drug absorption; it equals the (slope) of the feathered or stripped line and has been calculated from the following equation:

$K_{a b}=-\frac{\ln C_{\text {residual }}-\ln I_{A}}{t_{\text {early }}-0}$

$t_{1 / 2(a b)}$ gives a measure to determine the approximate time for drug absorption to be completed (after 3-5 half-lives for example); it was calculated in terms of $K_{a b}$ from the following equation:

$t_{1 / 2(a b)}=\frac{\ln 2}{K_{a b}}=\frac{0.693}{K_{a b}}$

It should be noted that the two straight lines of absorption and elimination should intercept almost at the same point on the $C_{p}$ axis. However, minor difference usually exists. The value of $I_{B}$ was used in equations of i.m. route in place of $C^{\circ}$ in equations after i.v. route; as $I_{B}$ is the back-extrapolated extension of the peak concentration $\left(C_{\max }\right)$.

The amount or fraction $(F)$ of lornoxicam that reaches circulation intact after i.m. administration was determined by comparing the area under the plasma C-T curve following a single i.m. administration $A U C_{(i m)}$ in normal rabbits with that calculated following single i.v. bolus injection $A U C_{(i v)}$. It was expressed in the following equation:

$F=\frac{A U C_{(i m)}}{A U C_{(i v)}} \times 100$

Where, AUC was the area under the plasma C-T curve, which gives the term of the total amount of the drug in the body. It was calculated by the trapezoidal rule and expressed as mg.h/L:

$A U C=\frac{C^{\circ}+C^{1}}{2}\left(t_{1}-t_{0}\right)+\frac{C^{1}+C^{2}}{2}\left(t_{2}-t_{1}\right)+$
$\frac{C^{2}+C^{3}}{2}\left(t_{3}-t_{2}\right)+\cdots+\frac{C^{\text {last }}}{\beta} \quad(m g \cdot h / L)$

It must be noted that $C^{\circ}$ here equals zero, unlike i.v. route where $C^{\circ}$ is the maximal concentration.

The parameters $\left(V_{d}\right)$ and $\left(C l_{B}\right)$ were calculated the same way after i.v. administration but with considering the value $(F)$ as follows:

$V_{d}=\frac{F * D * K_{a b}}{I_{B} *\left(K_{a b}-K_{e l}\right)}$

$\mathrm{V}_{\mathrm{d}}$ is just calculated here for determination of clearance. The $V_{d}$ after i.v. route $\left(V_{d(c)}, V_{d(\beta)} \& V_{d(s s)}\right)$ were relied.

$C l_{B}=V_{d} * K_{e l}$

$C l_{B}=\frac{F * D}{A U C}$

The presence of a peak in the plasma C-T profile is a characteristic for i.m. and other extravascular routes of administration. The peak 
can be described by the value of the peak plasma concentration $\left(C_{\max }\right)$ and the time at which it occurs $\left(T_{\max }\right)$. These two metrics can have an important influence on the drug response. The $T_{\max }$ can control the onset of action of the drug, and $C_{\max }$ may determine if the dose is sub-therapeutic, therapeutic, or toxic.

The values of $C_{\max }$ and $T_{\max }$ were easily be measured directly from the experimental data and also obtained from the following equations:

$$
\begin{aligned}
T_{\text {max }} & =\frac{\ln \left(K_{a b} / K_{e l}\right)}{K_{a b}-K_{e l}} \\
C_{\max } & =\frac{F * D}{V_{d}} * e^{-K_{e l} * T_{\max }}
\end{aligned}
$$

\subsection{Statistical analysis}

Standard computerized methods were used for analysis of obtained results, using peak height measurements on the recorded chromatograms. HPLC analysis of lornoxicam standard concentrations was done as triplicates; and means with standard error values were used for depicting the calibration curve. Concentrations of lornoxicam in unknown samples were determined using Trendfunction in $\mathrm{Excel}^{\circledR}$ by comparing their absorbance values with those of Standard lornoxicam concentrations. Concentration-Time tables and graphs were constructed for each animal after each dose administration. The pharmacokinetic variables of lornoxicam were calculated for each single animal; and data were expressed as means and standard error values from replicates $(n=6)$ using SPSS version 20 software (SPSS 2011).

\section{Results}

No clinical toxicity symptoms appeared on lornoxicamadministered rabbits, neither locally nor systemically. All birds were live throughout the experimental course.

\subsection{Standard calibration curve}

Figs. 2, 3, 4 and 5 are examples of the recorded chromatograms showing the peaks of absorbance (indicated by arrows) of the standard concentrations $(0,1,2 \& 4 \mu \mathrm{g} / \mathrm{mL})$ of lornoxicam in drug-free rabbit plasma.

Fig. 6 shows the standard curve of lornoxicam in drug-free plasma obtained by depicting all used concentrations from 0 to $8 \mu \mathrm{g} / \mathrm{mL}$.

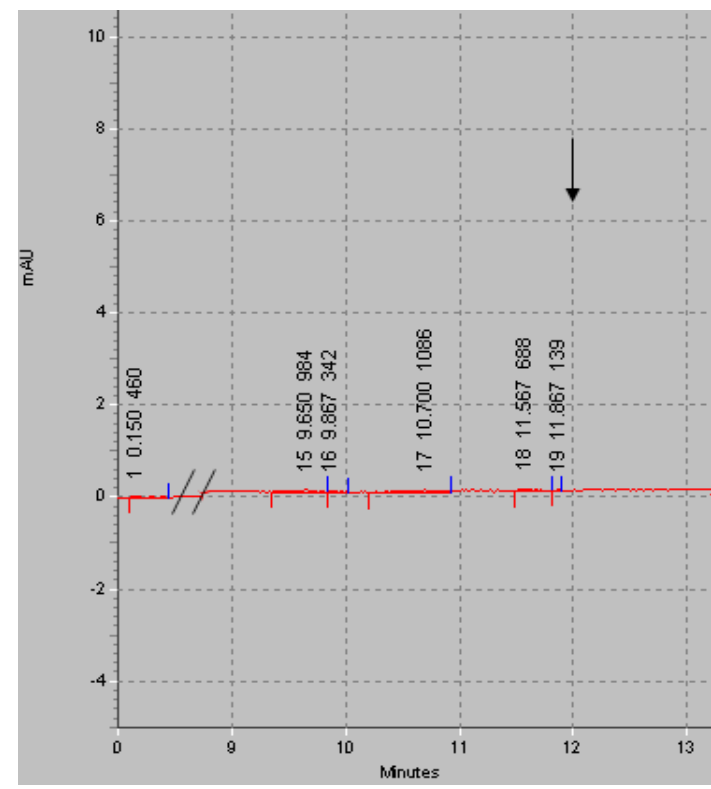

Fig. 2: Chromatogram Showing Peak of Absorbance (Indicated by Arrow) of the Standard Concentration ( $0 \mu \mathrm{g} / \mathrm{mL}$; Blank) of Lornoxicam in DrugFree Rabbit Plasma.

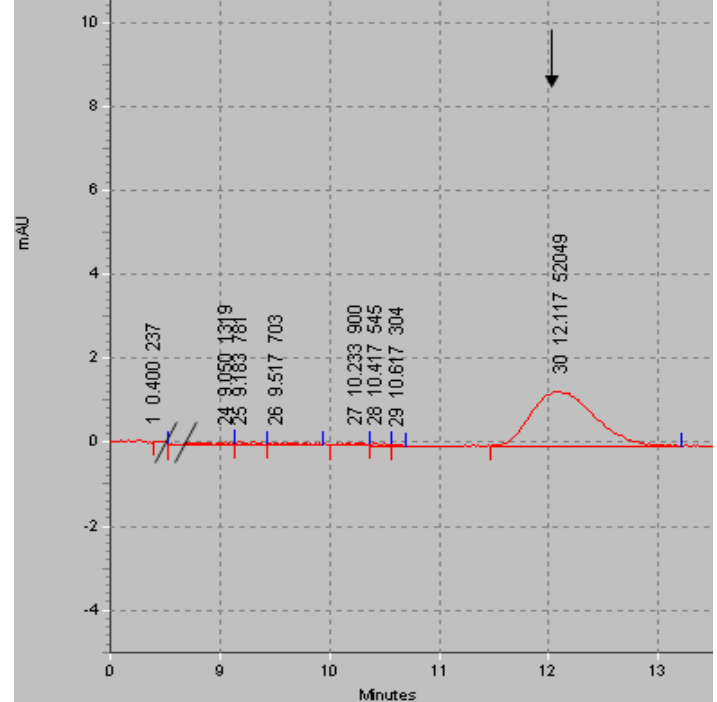

Fig. 3: Chromatogram Showing Peak of Absorbance (Indicated by Arrow) of the Standard Concentration $(1 \mu \mathrm{g} / \mathrm{mL})$ of Lornoxicam in Drug-Free Rabbit Plasma.

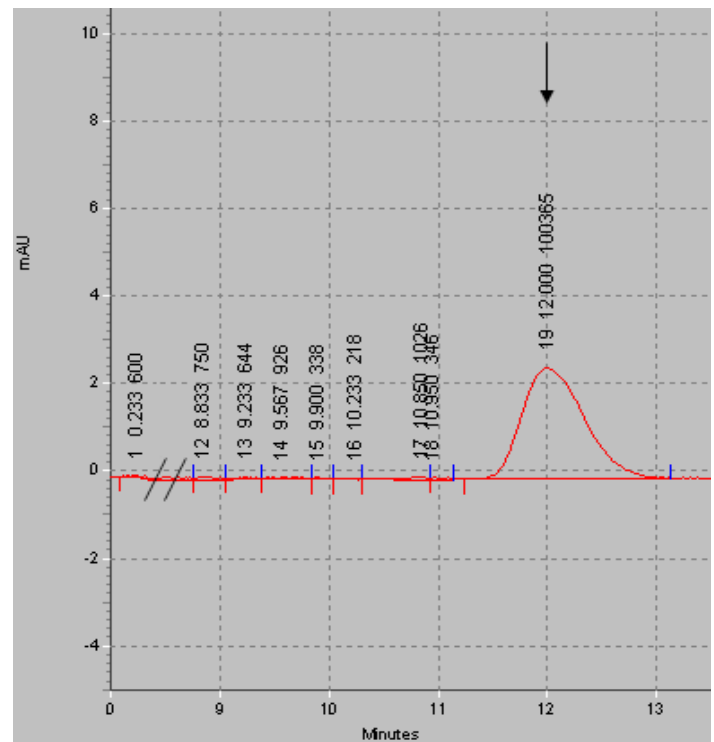

Fig. 4: Chromatogram Showing Peak of Absorbance (Indicated by Arrow) of the Standard Concentration $(2 \mu \mathrm{g} / \mathrm{mL})$ of Lornoxicam in Drug-Free Rabbit Plasma.

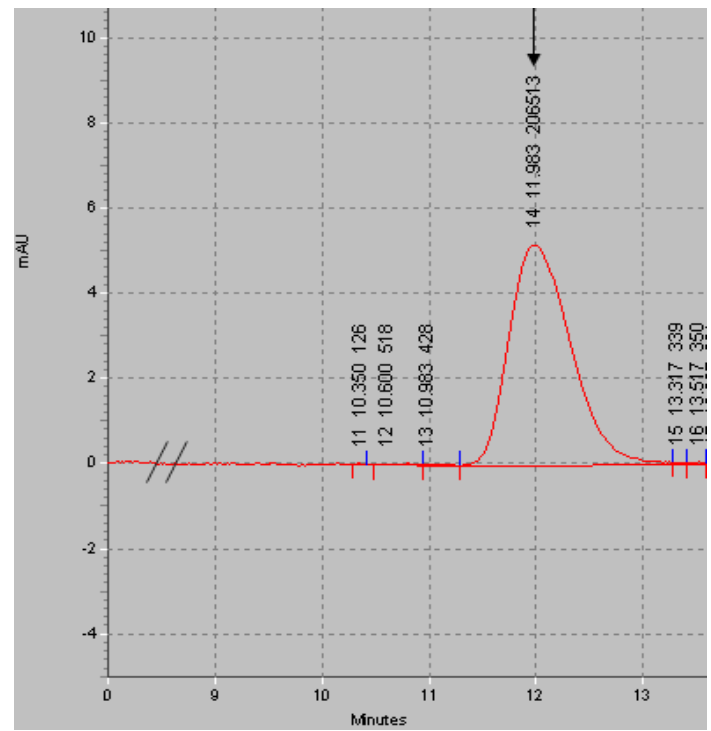

Fig. 5: Chromatogram Showing Peak of Absorbance (Indicated by Arrow) of the Standard Concentration $(4 \mu \mathrm{g} / \mathrm{mL})$ of Lornoxicam in Drug-Free Rabbit Plasma. 


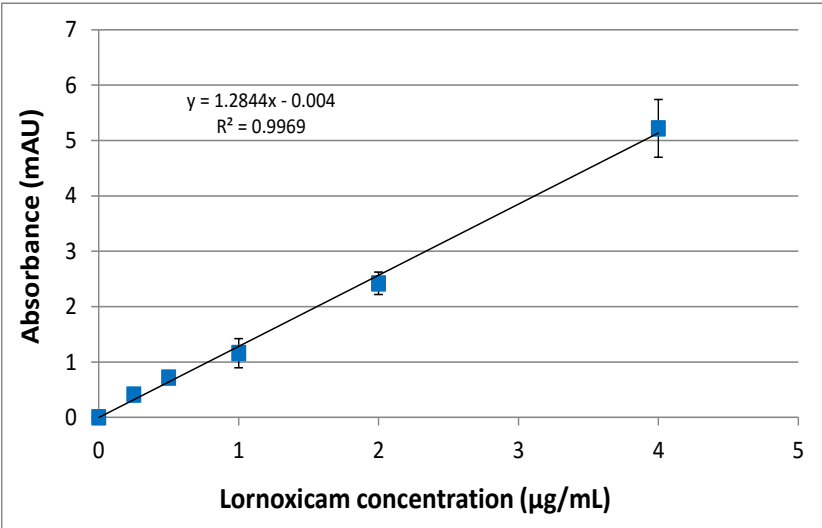

Fig. 6: Histogram Showing Standard Calibration Curve of Lornoxicam in Drug-Free Rabbit Plasma. Values are expressed as Means and Standard Errors of the Means of Triplicates.

\subsection{Plasma concentrations}

Fig. 7 shows Mean \pm SEM values of plasma concentration $(\mu \mathrm{g} / \mathrm{mL})$ of lornoxicam following single i.v. and i.m. bolus administrations at dose rate of $0.4 \mathrm{mg} / \mathrm{Kg}$ body weight to normal healthy rabbits (n $=6$ ). At $12 \mathrm{~h}$ bleeding points, the drug was not detected in all samples.

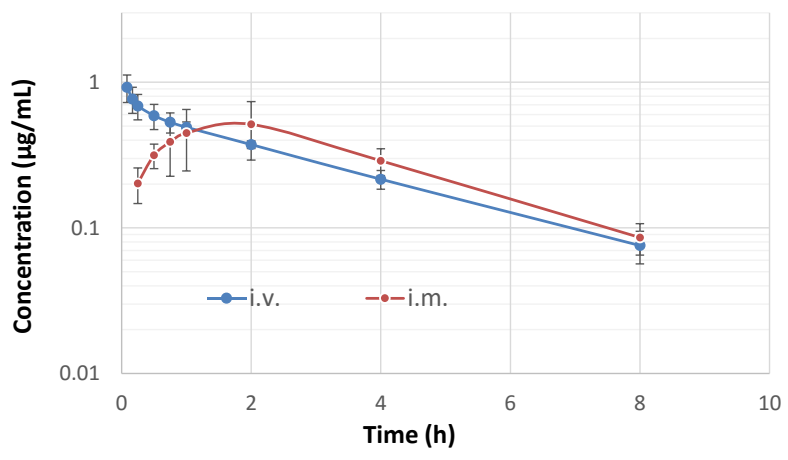

Fig. 7: Semi-Logarithmic Plot Showing Plasma Concentrations of Lornoxicam after I.V. and I.M. Single Bolus Administrations to Normal Rabbits along Time Course Up to $8 \mathrm{~h}$. Values are Expressed as Means and Standard Errors of the Means of 6 Observations.

\subsection{Pharmacokinetic parameters}

Pharmacokinetic parameters of lornoxicam in rabbits following single i.v. and i.m. bolus administrations of $0.4 \mathrm{mg} / \mathrm{Kg}$ body weight respectively are listed in Tables $1 \& 2$.

Table 1: Pharmacokinetic Parameters of Lornoxicam in Rabbits Following A Single I.V. Bolus Administration of $0.4 \mathrm{Mg} / \mathrm{Kg} \mathrm{B} \mathrm{Wt} .(\mathrm{N}=6)$.

\begin{tabular}{|c|c|}
\hline Parameter (unit) & Value $($ Mean \pm SEM) \\
\hline$\beta\left(\mathrm{hr}^{-1}\right)$ & $0.265 \pm 0.071$ \\
\hline $\mathrm{B}(\mathrm{mg} / \mathrm{L})$ & $0.626 \pm 0.144$ \\
\hline$\alpha\left(\mathrm{hr}^{-1}\right)$ & $2.914 \pm 0.212$ \\
\hline $\mathrm{A}(\mathrm{mg} / \mathrm{L})$ & $0.289 \pm 0.092$ \\
\hline $\mathrm{C}^{\circ}(\mathrm{mg} / \mathrm{L})$ & $0.905 \pm 0.113$ \\
\hline $\mathrm{T}^{1} 12_{\alpha}(\mathrm{hr})$ & $0.238 \pm 0.036$ \\
\hline $\mathrm{T}^{1} 1 / 2_{\beta}(\mathrm{hr})$ & $2.611 \pm 0.152$ \\
\hline $\mathrm{K}_{12}\left(\mathrm{hr}^{-1}\right)$ & $0.738 \pm 0.102$ \\
\hline $\mathrm{K}_{21}\left(\mathrm{hr}^{-1}\right)$ & $2.067 \pm 0.399$ \\
\hline $\mathrm{K}_{10}\left(\mathrm{hr}^{-1}\right)$ & $0.374 \pm 0.024$ \\
\hline AUC (mg.hr/L) & $2.420 \pm 0.330$ \\
\hline $\mathrm{V}_{\mathrm{c}}(\mathrm{L})^{*}$ & $1.105 \pm 0.122$ \\
\hline $\mathrm{V}_{\beta}(\mathrm{L})^{*}$ & $1.557 \pm 0.137$ \\
\hline $\mathrm{V}_{\mathrm{d}(\mathrm{ss})}(\mathrm{L})^{*}$ & $1.499 \pm 0.125$ \\
\hline $\mathrm{Cl}_{\mathrm{B}}(\mathrm{L} / \mathrm{hr})^{*}$ & $0.413 \pm 0.053$ \\
\hline $\mathrm{Cl}_{\mathrm{d}}(\mathrm{L} / \mathrm{hr})^{*}$ & $0.815 \pm 0.115$ \\
\hline $\mathrm{V}_{\mathrm{t}}(\mathrm{L})^{*}$ & $0.394 \pm 0.048$ \\
\hline
\end{tabular}

*The dose was applied as absolute dose not as $\mathrm{mg} / \mathrm{kg} \mathrm{b}$ wt, hence the unit.
Table 2: Pharmacokinetic Parameters of Lornoxicam in Normal Rabbits Following A Single I.M. Bolus Administration of $0.4 \mathrm{Mg} / \mathrm{Kg} \mathrm{B} \mathrm{Wt}$. (N = $6)$.

\begin{tabular}{ll}
\hline Parameter (unit) & Value (Mean \pm SEM) \\
\hline$\beta\left(\mathrm{hr}^{-1}\right)$ & $0.303 \pm 0.024$ \\
$\mathrm{~B}(\mathrm{mg} / \mathrm{L})$ & $0.973 \pm 0.092$ \\
$\alpha\left(\mathrm{hr}^{-1}\right)$ & $1.228 \pm 0.086$ \\
$\mathrm{~A}(\mathrm{mg} / \mathrm{L})$ & $0.964 \pm 0.037$ \\
$\mathrm{I}_{\mathrm{B}}(\mathrm{mg} / \mathrm{L})$ & $0.973 \pm 0.075$ \\
$\mathrm{~T}_{1 / 2 \mathrm{ab}}(\mathrm{hr})$ & $0.564 \pm 0.028$ \\
$\mathrm{~T}_{1 / 2 \mathrm{ll}}(\mathrm{hr})$ & $2.283 \pm 0.126$ \\
$\mathrm{~K}_{\mathrm{ab}}\left(\mathrm{hr}^{-1}\right)$ & $1.228 \pm 0.086$ \\
$\mathrm{~K}_{\mathrm{el}}\left(\mathrm{hr}^{-1}\right)$ & $0.303 \pm 0.024$ \\
$\mathrm{AUC}(\mathrm{mg} \cdot \mathrm{hr} / \mathrm{L})$ & $2.415 \pm 0.801$ \\
$\mathrm{~F}(\%)$ & $99.79 \pm 4.305$ \\
$\mathrm{~V}_{\mathrm{d}}(\mathrm{L})^{*}$ & $1.362 \pm 0.091$ \\
$\mathrm{Cl}_{\mathrm{B}}(\mathrm{L} / \mathrm{hr})^{*}$ & $0.413 \pm 0.043$ \\
$\mathrm{~T}_{\max }(\mathrm{hr})$ & $1.512 \pm 0.114$ \\
$\mathrm{C}_{\max }(\mathrm{mg} / \mathrm{L})$ & $0.463 \pm 0.018$ \\
\hline${ }^{*} \mathrm{The} d o s e$ was applied as absolute dose not as mg/Kg bwt, hence the unit.
\end{tabular}

\section{Discussion}

Pharmacokinetic studies are indispensable for the characterization of the time course of drug absorption, distribution, biotransformation and excretion. These processes orchestrate the potency and duration of effects of drugs (Baggot 1995). To produce its characteristic effect, a drug must attain effective concentrations at its site of action.

The need of pharmacokinetic investigations is further complicated in veterinary medicine by the variety of animal species to which therapeutic agents are administered. Wide variations in potency and duration of pharmacologic effects are commonly observed among species of domestic animals when a drug is given at the same dose and dosage (Baggot 1995). Species variations in response to drugs are attributed to differences in one of the following processes: systemic availability, accessibility to the site of action and the rate of elimination, including biotransformation and excretion (Dorrestein 1991). When a drug is administered by an extravascular route, the rate and extent of its absorption from its administration site are likely to vary between the species based on the anatomical and physiological differences. Similarly, the rate and extent of drug elimination vary among species based on anatomical and physiological differences in the renal system among different species. In addition, capacity and rate of biotransformation, and thus elimination, are vastly different due to the differences in liver microsomal enzyme activities among species (Watkins and Klaassen 1986).

The spectrum of action of NSAIDs includes analgesic, antiinflammatory and anti-pyretic effects which are very important in both human and veterinary medicine. The most important mechanism responsible for all three effects is the inhibition COX by its two isoenzymes that were discovered in 1990 (Botting 1999), and, subsequently, the reduced production of prostaglandins. Prostaglandins (primarily prostaglandin E2) sensitise the nocireceptors in the damaged tissue without triggering pain themselves. The blockade of prostaglandin synthesis leads to a peripheral as well as central inhibition of pain. The principal effect in the inflamed tissue is that the sensitisation of pain receptors is inhibited while the main effect in the central nervous system is the inhibition of synaptic transmission.

Lornoxicam, like all other NSAIDs, produces its action on the basis of inhibition of COX; an almost equivalent inhibition of COX-1 and COX-2 is achieved. Lornoxicam's potency of effect on the two COX isoenzymes in vitro is similar to that of diclofenac and about 100-fold more potent (on a molar basis) than that of tenoxicam. On account of its short half-life, no accumulation is likely to occur even in cases of repeated administration, in contrast to NSAID with a longer half-life. Due to these advantages, lornoxicam would be beneficial and safe drug to be used in veterinary medicine including food producing animals; however, there are no kinetic studies available for lornoxicam in such animals. This 
study, therefore, has been performed to evaluate the pharmacokinetic parameters in rabbits as a model for farm animals using a commercialized formulation of lornoxicam for human use that is $\mathrm{Xefo}^{\circledR}$.

The overall mean of plasma concentration-time profile of lornoxicam following a $0.4 \mathrm{mg} / \mathrm{kg}$ b wt, i.v. bolus dose in rabbits is shown in Fig. 7.

Following i.v. administration of lornoxicam to rabbits at a dose of $0.4 \mathrm{mg} / \mathrm{kg} \mathrm{b}$ wt, no adverse effects or toxic manifestation was observed indicating its preliminary safety. The results revealed that plasma lornoxicam concentration versus time decreased in a bi-exponential manner, demonstrating the presence of distribution and elimination phases and fitting to the two-compartment open model. Although there is no available data to compare with, yet this finding may be in agreement with that of (Heintz et al. 1983) who reported that tenoxicam in healthy human volunteers.

Table 1 report the overall mean for each pharmacokinetic parameter estimated for all studied rabbits after i.v. bolus administration The drug was rapidly distributed with a short $t^{1 / 2}(0.24 \mathrm{~h}) . T^{1 / 2}$ is the time taken for the blood concentration of the drug to decline by $50 \%$ during the distribution phase of the disposition curve. There is no available data to compare them with $t^{1 / 2} \alpha_{\alpha}$ after i.v. injection of lornoxicam.

The elimination half-life $\left(t^{1 / 2} \beta\right)$ was found to be $2.611 \mathrm{~h}$ in the present study. $T^{1 / 2 \beta}$ is the time taken for the blood concentration of the drug to decline by $50 \%$ during the elimination phase of the disposition curve. This result is shorter that that reported for piroxicam in cat, $11 \mathrm{~h}$ (Heeb et al. 2003); and for isoxicam in healthy volunteers, $28 \mathrm{~h}$ (Kölle and Vollmer 1986); and for tenoxicam in healthy volunteers, $72 \mathrm{~h}$ (Heintz et al. 1983).

The volume of distribution of a drug is a ratio of the amount of drug in the body at any time to the plasma concentration at that time. In a two-compartment model the volume of distribution changes after the administration of a dose, and at different times one of three volumes of distribution may hold, $V_{c}, V_{\beta}$, and $V_{d(s s)}$. Among them the latter is the most reliable. At time zero the entire dose was contained within the central compartment and $V_{d}=V_{c}$. The drug then gradually distributes to the peripheral compartment $\left(V_{t}\right)$. As the physical volume through which the drug distributes increases, the volume of distribution increases. At steady state the loss of drug from elimination was matched exactly by the gain of drug from administration.

In the present study, the value of $V_{d(s s)}$ was found to be about (1.5 L) indicates large extravascular distribution of the drug. Total blood volume in rabbit is $56 \mathrm{ml} / \mathrm{Kg}$ in average, viz a rabbit weighing $2.5 \mathrm{Kg}$ may have about $140 \mathrm{~mL}$ of blood. Nevertheless, this relatively large $V_{d(s s)}$ of lornoxicam is inconsistent with that reported for tenoxicam in healthy volunteers, $20-40 \%$ of body weight (Heintz et al. 1983); and for piroxicam in cat, $0.48 \mathrm{~L} / \mathrm{Kg}$ (Heeb et al. 2003). It is worthy to note that the unit used depends on whether the dose of the administered drug was calculated as absolute dose (in such case $\mathrm{L}$ is used as the unit for distribution) or in units of weight per weight, i.e. $\mathrm{mg} / \mathrm{Kg}$, (in such case $\mathrm{L} / \mathrm{Kg}$ is used to describe drug distribution).

Total clearance of a drug from the body is expressed in terms of the volume of blood cleared of the drug by the various elimination processes (biotransformation and excretion) per unit time and body weight. It represents the sum of all clearance processes. Therefore, it is a measure of the ability of the organs of elimination to remove drug from the plasma, and it is a constant of proportionality between the rate of elimination at any time and the corresponding plasma concentration. In the present study, the total body clearance of lornoxicam following i.v. administration was $0.41 \mathrm{~L} / \mathrm{h}$. The value may be larger than that reported for tenoxicam in healthy volunteers, $1.3-4.2 \mathrm{~mL} / \mathrm{min}$ (Heintz et al. 1983); and than that reported for piroxicam in cats, $0.031 \mathrm{~L} / \mathrm{h} / \mathrm{Kg}$ (Heeb et al. 2003).

After i.m. administration, plasma concentration-time profiles of lornoxicam at a dose of $0.4 \mathrm{mg} / \mathrm{Kg} \mathrm{b}$ wt, i.m. bolus in rabbits are depicted in Fig. 7.
Table 2 report the overall mean for each pharmacokinetic parameter estimated for all studied rabbits after i.m. bolus administration. Following i.m. administration of lornoxicam to rabbits at a dose of $0.4 \mathrm{mg} / \mathrm{Kg}$ bw, the drug was moderately rapidly absorbed with an intermediate absorption half-life $t_{1 / 2(a b)}$ of $0.56 \mathrm{~h}$. This value was longer than that reported for isoxicam in man, $0.24 \mathrm{~h}$ (Kölle and Vollmer 1986). Absorption parameters for lornoxicam were studied after oral administration not after i.m. administration. Therefore, unfortunately, there is no parallel data available in literature to compare with.

Maximal plasma concentrations $\left(C_{\max }\right)$ mean value was 0.46 $\mu \mathrm{g} / \mathrm{mL}$. All animals reached $C_{\max }$ at time to peak of 1.51 hours after dosing $\left(T_{\max }\right)$. No i.m. data are available for lornoxicam to compare with, however, these results are inconsistent with values reported after isoxicam in man (Kölle and Vollmer 1986) who found that isoxicam reaches $11.7 \mathrm{mg} / \mathrm{L}$ after 3.4 hours. It has been reported that lornoxicam is completely absorbed after oral administration, and reaches $270 \mu \mathrm{g} / \mathrm{L}$ within 2.5 hours after a $4 \mathrm{mg}$ dose in man (Balfour et al. 1996).

The elimination half-life of lornoxicam following i.m. administration of $0.4 \mathrm{mg} / \mathrm{Kg}$ bw to rabbits was $2.28 \mathrm{~h}$ in the present study. This value is shorter than that reported for isoxicam in man, $27.1 \mathrm{~h}$ (Kölle and Vollmer 1986). T1/2el of lornoxicam after oral administration in young man was ranging between 3-5 h (Balfour et al. 1996).

The value of systemic bioavailability calculated in this study was 99.79\%, indicating almost complete absorption of lornoxicam from i.m. administration site. Bioavailability is the amount or fraction $(F)$ in $\%$ of lornoxicam that reaches circulation intact after extravascular administration (i.m. in this study). It was determined by comparing the area under the plasma C-T curve following a single i.m. administration $A U C_{(i m)}$ in normal rabbits with that calculated following single i.v. injection $A U C_{(i v)}$. This value was comparable with that reported for isoxicam in man, 104\% (Kölle and Vollmer 1986). Absorption of lornoxicam was without first pass effect and thus was complete after oral administration to healthy volunteers (Balfour et al. 1996).

Complete bioavailability of lornoxicam and maintenance of its therapeutic concentration up to $8 \mathrm{~h}$ after i.m. administration suggests that the drug is suitable for i.m. administration for the treatment of systemic and local affections in rabbits. This may be explained on the basis of protein binding capacity of lornoxicam that was found to be $98.9 \%$ in rabbits' plasma in this study. This value of plasma protein binding capacity is consistent with that recorded in man, 99\% (Balfour et al. 1996).

\section{Conclusion}

It could be concluded that the disposition of lornoxicam after intravenous administration of $0.4 \mathrm{mg} / \mathrm{Kg}$ bw, to rabbits is best described by a bi-exponential regression and best-fit to twocompartment open model. Bioavailability after intramuscular administration was complete and adequate drug concentration was recorded up to $8 \mathrm{~h}$ post administration with plasma protein binding capacity of $98.9 \%$. The study recommends the use of lornoxicam in rabbits because of its good pharmacokinetic profile.

\section{Acknowledgements}

The author would like to thank Dr. Othman El-Mahmoudy, Methodology \& Stability Section, Research \& Development Department, Sigma Pharmaceutical Co., Quesna, Egypt, for kind gifting lornoxicam standard powder.

Thanks are also attributed to Prof. Dr. Sabry El-Khodery, Department of Animal Medicine, Mansoura University, Egypt, for kind help in blood sampling. 


\section{References}

[1] Baggot J 1995, Pharmacokinetics: disposition and fate of drugs in the body. Veterinary pharmacology and therapeutics 18-52.

[2] Baggot JD 1977, Principles of drug disposition in domestic animals: the basis of veterinary clinical pharmacology: WB Saunders.

[3] Baggot JD 1978a, Some aspects of clinical pharmacokinetics in veterinary medicine II. Journal of Veterinary Pharmacology and Therapeutics 1, 111-118. http://dx.doi.org/10.1111/j.13652885.1978.tb00314.x.

[4] Baggot JD 1978b, Some aspects of clinical pharmacokinetics in veterinary medicine. I. Journal of Veterinary Pharmacology and Therapeutics 1, 5-18. $\quad$ http://dx.doi.org/10.1111/j.13652885.1978.tb00300.x

[5] Balfour JA, Fitton A \& Barradell LB 1996, Lornoxicam. A review of its pharmacology and therapeutic potential in the management of painful and inflammatory conditions. Drugs 51, 639-657. http://dx.doi.org/10.2165/00003495-199651040-00008.

[6] Bhandari S \& Khisti N 2012, Extraction-less high-performance liquid chromatographic method for determination of lornoxicam in human plasma. Asian Journal of Pharmaceutical and Clinical Research 5, 122-124.

[7] Botting JH 1999, Nonsteroidal antiinflammatory agents. Drugs Today 35, 225. http://dx.doi.org/10.1358/dot.1999.35.4-5.552199.

[8] Copeland RA, Williams JM, Giannaras J, Nurnberg S, Covington M, Pinto D, Pick S \& Trzaskos JM 1994, Mechanism of selective inhibition of the inducible isoform of prostaglandin $\mathrm{G} / \mathrm{H}$ synthase. Proceedings of the National Academy of Sciences 91, 1120211206. http://dx.doi.org/10.1073/pnas.91.23.11202.

[9] Craig W \& Suh B 1991, Protein binding and the antimicrobia effects: methods for the determination of protein binding. Antibiotics in laboratory medicine Williams \& Wilkins, Baltimore, Md 367-402.

[10] Dorrestein GM 1991, The pharmacokinetics of avian therapeutics. Veterinary Clinics of North America: Small Animal Practice 21, 1241-1264. http://dx.doi.org/10.1016/S0195-5616(91)50135-2.

[11] El Dareer SM, Noker PE \& and Galbraith WM 1990, Disposition of [14C] lornoxicam in male and female cynomolgus monkeys dosed orally or intravenously. The FASEB Journal 4, A461 (Abstr. 1132).

[12] Grizzle JE 1965, The two-period change-over design and its use in clinical trials. $\quad$ Biometrics http://dx.doi.org/10.2307/2528104.

[13] Heeb H, Chun R, Koch D, Goatley M \& Hunter R 2003, Single dose pharmacokinetics of piroxicam in cats. Journal of Veterinary Pharmacology and Therapeutics 26, 259-263. http://dx.doi.org/10.1046/j.1365-2885.2003.00479.x.

[14] Heintz R, Guentert T, Enrico J, Dubach U, Brandt R \& Jeunet F 1983, Pharmacokinetics of tenoxicam in healthy human volunteers. European Journal of Rheumatology and Inflammation 7, 33-44.

[15] Hitzenberger G, Radhofer-Welte S, Takacs F \& Rosenow D 1989 Pharmacokinetics of lornoxicam in man. Postgraduate Medical Journal 66, S22-27.

[16] Kölle E \& Vollmer K-O 1986, Pharmacokinetics of isoxicam following intravenous, intramuscular, oral and rectal administration in healthy volunteers. British Journal of Clinical Pharmacology 22, 135S. http://dx.doi.org/10.1111/j.1365-2125.1986.tb02995.x.

[17] Liang Y, Shi Q \& Zhou Y-w 2006, Pharmacokinetics and bioequivalence of lornoxicam tablet in healthy volunteers. Chinese Journal of Clinical Pharmacology 22, 336.

[18] Lirk P, Seymour R-A, Ong C-K-S \& Tan C-H 2007, An evidencebased update on nonsteroidal anti-Inflammatory Drugs. Clin Med Res 5, 19-34. http://dx.doi.org/10.3121/cmr.2007.698

[19] Merck-Veterinary-Manual 2016, Nonsteroidal antiinflammatory drugs. Available http://www.merckvetmanual.com/mvm/pharmacology/antiinflammatory_agents/nonsteroidal_anti-inflammatory_drugs.html.

[20] Pabst G \& Jaeger H 1990, Review of methods and criteria for the evaluation of bioequivalence studies. European Journal of Clinical Pharmacology 38, 5-10. http://dx.doi.org/10.1007/BF00314794.

[21] Paget G \& Barnes J 1964, Toxicity tests. Evaluation of drug activities: Pharmacometrics 1, 135.

[22] Prasad Byrav D, Medhi B, Prakash A, Patyar S \& Wadhwa S 2009, Lornoxicam: a newer NSAID. IJPMR 20, 27-31.

[23] Radhofer-Welte S \& Rabasseda X 2000, Lornoxicam, a new potent NSAID with an improved tolerability profile. Drugs Today $36,55-$ 76. http://dx.doi.org/10.1358/dot.2000.36.1.566627.

[24] Riegelman S, Loo J \& Rowland M 1968, Shortcomings in pharmacokinetic analysis by conceiving the body to exhibit properties of a single compartment. Journal of Pharmaceutical Sciences 57, 117-123. http://dx.doi.org/10.1002/jps.2600570123.

[25] Riggs DS 1964, The Mathematical Approach to Physiological Problems. Academic Medicine 39, 235.

[26] Rosenbaum SE 2012, Basic pharmacokinetics and pharmacodynamics: An integrated textbook and computer simulations: John Wiley \& Sons.

[27] SPSS IBM 2011, Version 20. New York, NY, USA: IBM Incorporation.

[28] Watkins J \& Klaassen CD 1986, Xenobiotic biotransformation in livestock: comparison to other species commonly used in toxicity testing. Journal of Animal Science 63, 933-942.

[29] Zhang Y, Zhong D, Si D, Guo Y, Chen X \& Zhou H 2005 , Lornoxicam pharmacokinetics in relation to cytochrome P450 2C9 genotype. British Journal of Clinical Pharmacology 59, 14-17. http://dx.doi.org/10.1111/j.1365-2125.2005.02223.x. 